\title{
Structural and physical properties of the new layered transition metal material $\mathrm{Na}_{4} \mathrm{Cu}_{3} \mathrm{TaAs}_{4}$
}

\author{
Fanbao Meng ${ }^{1}$, Mengzhu Shi ${ }^{1}$, Shengtao Cui ${ }^{2}$, Kunling Peng ${ }^{1}$, Naizhou Wang ${ }^{1}$, Zhe Sun $^{2}$, \\ Jianjun Ying $^{1}$ and Xianhui Chen ${ }^{1,3,4,5^{*}}$
}

\begin{abstract}
We report the synthesis, structural and physical properties of a new layered transition metal arsenide $\mathrm{Na}_{4} \mathrm{Cu}_{3} \mathrm{TaAs}_{4}$. This material adopts the space group $I \overline{4} 2 \mathrm{~m}$, with lattice parameters of $a=5.9101$ (3) $\AA$ and $c=13.8867$ (12) $\AA$. This structure contains two layers of $\mathrm{Na}$ sandwiched by antiPbO-type (Cu/Ta)As layers, similar to the "111"-type ironbased superconductor $\mathrm{NaFeAs}$. The transition metal sites are occupied by $75 \% \mathrm{Cu}$ and $25 \% \mathrm{Ta}$, with Ta forming a welldefined $\sqrt{2} \times \sqrt{2} \times 2$ superstructure. $\mathrm{Cu}$ and Ta were determined to be +1 and +5 oxidation state respectively. The band structure of the $\mathrm{Na}_{4} \mathrm{Cu}_{3} \mathrm{TaAs}_{4}$ measured by angle resolved photoemission spectroscopy (ARPES) is in good agreement with the density functional theory (DFT) calculation. Both ARPES and resistivity measurement indicate that this material exhibits metallic behavior with p-type carriers. Magnetic susceptibility measurement shows that the material exhibits nearly $T$-independent diamagnetism. This new material extends the material system with anti-PbO-type layers and offers a good playground to investigate this material system further.
\end{abstract}

Keywords: layered arsenide, anti-PbO-type layer, superstructure, band structure, physical properties

\section{INTRODUCTION}

Layered transition metal materials with anti-PbO-type pnictide or chalcogenide layers have been studied extensively due to their diverse properties. Anti-PbO-type layer can be described as MX (M=transition metal, $\mathrm{X}=\mathrm{As}$, $\mathrm{P}, \mathrm{Se}$ ) layer composed of edge-sharing $\mathrm{MX}_{4}$ tetrahedra, which plays a crucial role in physical properties. Among these materials, the most famous one may be the ironbased superconductors with FeAs(Se) layers [1-7], which exhibit unconventional superconductivity with the highest transition temperatures $T_{\mathrm{c}}>50 \mathrm{~K}$. Besides high- $T_{\mathrm{c}}$ superconductivity, materials with ani- $\mathrm{PbO}$-type layers also have interesting magnetic [8-11], optical [12] and thermoelectric [13] properties. For example, LaOMnAs with MnAs layers exhibits large negative magnetoresistance [10].

In addition, materials with variants of the anti-PbOtype MX layer also have been studied extensively. One of the variants is $\left[\mathrm{MSe}_{2}\right]^{2-}$-type layer in $\mathrm{Ln}_{2} \mathrm{O}_{2} \mathrm{MSe}_{2}(\mathrm{Ln}=\mathrm{La}$, $\mathrm{Ce})$, which is induced by half-occupancy of the transitionmetal and exhibits diverse cation-ordered structures. For example, in $\mathrm{La}_{2} \mathrm{O}_{2} \mathrm{CdSe}_{2}$ with $\left[\mathrm{CdSe}_{2}\right]^{2-}, \mathrm{Cd}^{2+}$ cations occupy alternate tetrahedral sites, forming a $\sqrt{2} \times \sqrt{2} \mathrm{su}$ perstructure in the $a b$ plane relative to perfect anti- $\mathrm{PbO}$ type MX layer [14]. Whereas in $\mathrm{La}_{2} \mathrm{O}_{2} \mathrm{FeSe}_{2},\left[\mathrm{FeSe}_{2}\right]^{2-}$ layers contain $1 \mathrm{D}$ chains of edge-sharing (stripe-like) $\mathrm{FeSe}_{4}$ tetrahedra [15]. This kind of variant can be considered as anti-PbO-type MX layers composed by ordered transition metal elements and vacancies. Another variant is MX layer composed by two kinds of transition metal elements, which also exhibits cation-ordered structure. Materials containing this kind of variant are rare. Only one compound, $\mathrm{NaFe}_{0.5} \mathrm{Cu}_{0.5} \mathrm{As}$, has been reported, in which $\mathrm{Fe}^{3+}$ and $\mathrm{Cu}^{1+}$ arrange orderly, forming $2 \times 2 \mathrm{su}-$ perstructure [16]. Except for $\mathrm{Fe}$ and $\mathrm{Cu}$ ordering, $\mathrm{NaFe}_{0.5} \mathrm{Cu}_{0.5}$ As also exhibits antiferromagnetic Mottinsulating state which connects with high- $T_{c}$ superconductivity. Considering the interesting structural fea-

\footnotetext{
${ }^{1}$ Key Laboratory of Strongly Coupled Quantum Matter Physics, Chinese Academy of Sciences, Hefei National Laboratory for Physical Sciences at Microscale, Department of Physics, University of Science and Technology of China, Hefei 230026, China

${ }^{2}$ National Synchrotron Radiation Laboratory, University of Science and Technology of China, Hefei 230026, China

${ }^{3}$ Collaborative Innovation Center of Advanced Microstructures, Nanjing University, Nanjing 210093, China

${ }^{4}$ CAS Center for Excellence in Superconducting Electronics (CENSE), Shanghai 200050, China

${ }^{5}$ CAS Center for Excellence in Quantum Information and Quantum Physics, Hefei 230026, China

* Corresponding author (email: chenxh@ustc.edu.cn)
} 
tures and physical properties of this kind of material, more work is needed to explore this material system.

In our current research, we synthesized a new layered $\mathrm{Na}_{4} \mathrm{Cu}_{3} \mathrm{TaAs}_{4}$ single crystal with anti-PbO-type $(\mathrm{Cu} / \mathrm{Ta})$ As layers composed by ordered $\mathrm{Cu}$ and $\mathrm{Ta}$. The crystal structure of the new material was determined by single crystal X-ray diffraction (XRD) technique. Ta forms $\sqrt{2} \times \sqrt{2} \times 2$ superstructure. $\mathrm{Cu}$ and $\mathrm{Ta}$ were determined to be +1 and +5 oxidation state by X-ray photoelectron spectroscopy (XPS) respectively. The dispersion relations measured by angle resolved photoemission spectroscopy (ARPES) are in good agreement with theoretical calculation. ARPES and resistivity measurement both show that the new material exhibits metallic behavior. And magnetic susceptibility measurement indicates that the new material exhibits diamagnetism.

\section{EXPERIMENTAL SECTION}

\section{Synthesis and analysis}

High-quality $\mathrm{Na}_{4} \mathrm{Cu}_{3} \mathrm{TaAs}_{4}$ single crystal was grown by a self-flux technique which was similar to the synthesis method of $\mathrm{NaFe}_{1-x} \mathrm{Co}_{x} \mathrm{As}$ [17]. The single crystal was commenced from the elements, handled in an argonfilled glovebox. The NaAs was used as flux to synthesize the sample. Firstly, NaAs precursor was prepared. $\mathrm{Na}$ pieces and As powder ground from As lumps were weighted at the molar ratio of $1: 1$ and sealed in quartz ampoule, then reacted at $200^{\circ} \mathrm{C}$ for $10 \mathrm{~h}$. Secondly, the $\mathrm{NaAs}$ precursor was mixed with the $\mathrm{Cu}$ powder (Alfa Aesar, 600 mesh, 99.5\%) and Ta powder (Alfa Aesar, $\sim 100$ mesh, $99.5 \%)$ at the molar ratio of $\mathrm{Na}: \mathrm{As}: \mathrm{Cu}$ : $\mathrm{Ta}=4: 4: 0.75: 0.25$. The mixture was thoroughly ground and sealed in tantalum crucibles. Then the crucibles were sealed in a quartz tube under a vacuum of approximately $1 \times 10^{-3}$ mbar. Thirdly, the reaction was conducted in a pit furnace to get high quality single crystals. The quartz tubes were heated to $950^{\circ} \mathrm{C}$ at the rate of $100^{\circ} \mathrm{C} / \mathrm{h}$ and kept at this temperature for $10 \mathrm{~h}$ and then cooled to $650^{\circ} \mathrm{C}$ at the rate of $3^{\circ} \mathrm{C} / \mathrm{h}$. Finally, high-quality single crystals could be picked from NaAs flux easily. The single crystals can be cleaved and the sizes of the single crystals were typically $3 \mathrm{~mm} \times 2 \mathrm{~mm} \times 0.3 \mathrm{~mm}$. We could cleave the single crystals by using a blade to obtain fresh and clean surface for measurements. Both single-crystal and polycrystalline samples were used in this study. The polycrystalline samples were prepared by crushing the single crystal into fragments thoroughly in the glove box. It is worthy to note that the $\mathrm{Na}_{4} \mathrm{Cu}_{3} \mathrm{TaAs}_{4}$ single crystals are sensitive to air and moisture. In order to obtain intrinsic physical properties, the samples must be stored and transported in sealed containers filled with an insert gas.

The single-crystal and polycrystalline samples were characterized by X-ray diffractometer (Smartlab-9, Riga$\mathrm{ku}$ Corp) with $\mathrm{Cu} \mathrm{Ka}$ radiation and a fixed graphite monochromator in the range of $10^{\circ}-70^{\circ}$ at room temperature.

To determine the actual chemical composition of the single crystal, energy-dispersive X-ray analysis (EDX) was performed on the single crystal by using the field emission scanning electron microscope (FE-SEM SIRION 200) with an additional EDX device. The ratio of $\mathrm{Na}, \mathrm{Cu}$, $\mathrm{Ta}$ and As was determined to be 32.943:25.590:8.771: 32.697 (in atom\%). And the chemical formula could be identified as $\mathrm{Na}_{4} \mathrm{Cu}_{3} \mathrm{TaAs}_{4}$ (i.e., $\mathrm{NaCu}_{0.75} \mathrm{Ta}_{0.25} \mathrm{As}$ ). Any additional elements were not found. The EDX spectra and chemical compositions at different areas of the $\mathrm{Na}_{4} \mathrm{Cu}_{3} \mathrm{TaAs}_{4}$ single crystals are shown in Fig. S1 and Table S1 (see Supplementary information (SI)).

The valences of $\mathrm{Cu}, \mathrm{Ta}$, As and $\mathrm{Na}$ in the single crystal were determined with XPS by using an ESCAlab250 XPS with monochromatized $\mathrm{Al} \mathrm{Ka} \mathrm{X-ray} \mathrm{source.}$

\section{Crystal structure determinations}

A single crystal XRD technique was also performed to give insight into atomic crystal structures. A shinny single crystal with the size of $0.2 \mathrm{~mm} \times 0.1 \mathrm{~mm} \times 0.03 \mathrm{~mm}$ was selected using the microscope and then mounted on a glass fiber. Single crystal XRD data were collected by using an Oxford Diffraction Gemini S Ultra CCD diffractometer equipped with graphite-monochromatized Mo Ka $(\lambda=0.7107 \AA)$ radiation at $293 \mathrm{~K}$. Then the crystal structures were resolved by direct methods and the data refinement was done by using the full-matrix leastsquares methods with SHELXL-2018 programs [18].

\section{Calculation of the band structure}

The projector augmented plane wave (PAW) $[19,20]$ method as implemented in the Vienna ab initio simulation package (VASP) [21] code was used for structure relaxation. The exchange-correlation function was defined by using a generalized gradient approximation (GGA) of Perdew-Burke-Ernzerhof (PBE) [22]. The total energies were numerically converged to $1 \times 10^{-6} \mathrm{eV}$ by using a kinetic energy cutoff of $500 \mathrm{eV}$. The atomic positions were relaxed until the forces on the atoms were smaller than $0.01 \mathrm{eV} \AA^{-1}$. For the Brillouin zone integrations, we used the Monkhorst-Park k-mesh scheme with $9 \times 9 \times 9$ for the primitive cell $(I 42 m, 12$ atoms $)$. 


\section{Physical property measurements}

ARPES experiments were performed with $90 \mathrm{eV}$ photos at the beamline 13U of the National Synchrotron Radiation Laboratory (NSRL) at Hefei, China, by using a Scienta R4000 electron spectrometer. All samples were cleaved in situ and measured at $300 \mathrm{~K}$ under a vacuum less than 5 $\times 10^{-11}$ mbar. The temperature dependence of resistivity was measured by a standard four-probe method. Because the single crystal was sensitive to the air, the electrodes were made in the glove box with high pure Argon gas and the electrical transport measurement was conducted on PPMS-9 T (Quantum Design). The magnetic susceptibility was measured by a SQUID magnetometer (MPMS5 T, Quantum Design).

\section{RESULTS}

The single crystal and polycrystalline XRD patterns of $\mathrm{Na}_{4} \mathrm{Cu}_{3} \mathrm{TaAs}_{4}$ collected at room temperature are shown in Fig. 1. As shown in Fig. 1a, the XRD pattern of $\mathrm{Na}_{4} \mathrm{Cu}_{3} \mathrm{TaAs}_{4}$ single crystal sample exhibits a highly (001)

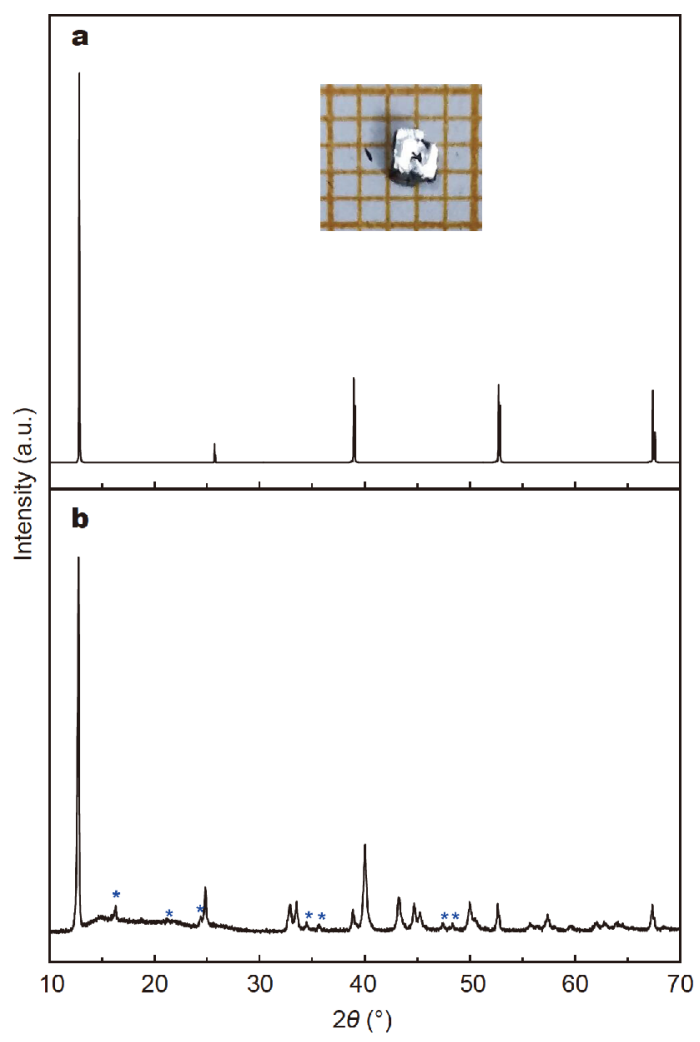

Figure 1 The XRD patterns taken from $\mathrm{Na}_{4} \mathrm{Cu}_{3} \mathrm{TaAs}_{4}$ single crystal and polycrystalline samples. (a) The single crystal XRD pattern shows a series of (001) diffractions. The inset shows the photograph of the single crystal. (b) The powder XRD pattern. Excrescent peaks compared to $\mathrm{NaFeAs}$ are marked with blue asterisks. orientation, indicating that the single crystal is of high quality. The polycrystalline XRD pattern shown in Fig. $1 \mathrm{~b}$ is similar to that of known "111"-type Fe-based superconductor [23]. And the main diffraction peaks in the XRD pattern can be well indexed by the structure of $\mathrm{NaFeAs}$ except for some peaks with relatively weak intensity (blue stars), demonstrating that the new material has the same basic structure as NaFeAs. Therefore, the chemical formula of the new material can be written as $\mathrm{NaCu}_{0.75} \mathrm{Ta}_{0.25} \mathrm{As}$, in which equivalently $25 \% \mathrm{Cu}$ is replaced by $\mathrm{Ta}$ in the parent compound "NaCuAs", although the parent cannot be synthesized yet. And these excrescent weak peaks may stem from orderly arrangement of Ta, which is similar to superstructure peaks in $\mathrm{NaFe}_{1-x} \mathrm{Cu}_{x}$ As originating from $\mathrm{Cu}$ cations doping [16] and $\mathrm{K}_{2} \mathrm{Fe}_{4} \mathrm{Se}_{5}$ originating from the ordered vacancies of the $\mathrm{Fe}[24,25]$.

In order to determine the accurate crystal structure of $\mathrm{Na}_{4} \mathrm{Cu}_{3} \mathrm{TaAs}_{4}$, we performed further structural investigation by means of single crystal XRD technique. The resulting structure is shown in Fig. 2. The crystal structure of $\mathrm{Na}_{4} \mathrm{Cu}_{3} \mathrm{TaAs}_{4}$ has five independent crystallographic positions: two positions are occupied by $\mathrm{Cu}$, one position occupied by $\mathrm{Na}$, one position occupied by $\mathrm{Ta}$ and the remaining one occupied by As. The crystallographic data of $\mathrm{Na}_{4} \mathrm{Cu}_{3} \mathrm{TaAs}_{4}$ is shown in Table 1. The atomic positions and displacement parameters are summarized in Table 2. And the interatomic distances are
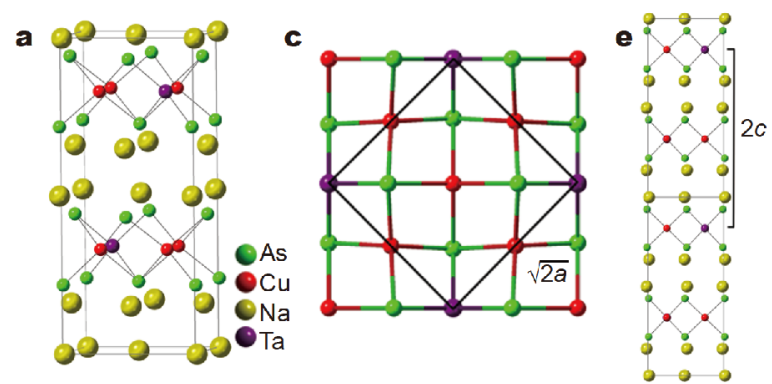

b

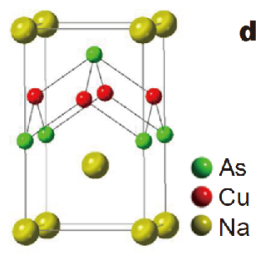

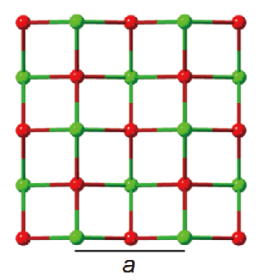

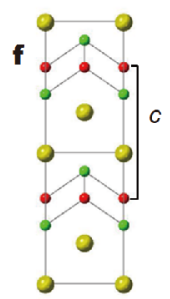

Figure 2 The structure of $\mathrm{Na}_{4} \mathrm{Cu}_{3} \mathrm{TaAs}_{4}$ and "parent" $\mathrm{NaCuAs}$. (a, b) Schematic illustration of the crystal structure of the $\mathrm{Na}_{4} \mathrm{Cu}_{3} \mathrm{TaAs}_{4}$ and "NaCuAs". (c, d) $(\mathrm{Cu} / \mathrm{Ta})$ As nets of the $\mathrm{Na}_{4} \mathrm{Cu}_{3} \mathrm{TaAs}_{4}$ and $\mathrm{CuAs}$ nets of the "NaCuAs" in the $a b$ plane. (e, f) Structures of the $\mathrm{Na}_{4} \mathrm{Cu}_{3} \mathrm{TaAs}_{4}$ and the "NaCuAs" along the $c$ direction. 
Table 1 Crystallographic data for $\mathrm{Na}_{4} \mathrm{Cu}_{3} \mathrm{TaAs}_{4}$

\begin{tabular}{|c|c|}
\hline Parameters & Values \\
\hline Chemical formula & $\mathrm{Na}_{4} \mathrm{Cu}_{3} \mathrm{TaAs}_{4}$ \\
\hline Formula weight $\left(\mathrm{g} \mathrm{mol}^{-1}\right)$ & 763.21 \\
\hline Temperature (K) & $293(2) \mathrm{K}$ \\
\hline Wavelength $(\AA)$ & 0.71073 \\
\hline Crystal system & Tetragonal \\
\hline Space group & $I \overline{4} 2 m(121)$ \\
\hline$a(\AA)$ & $5.9101(3)$ \\
\hline$b(\AA)$ & $5.9101(3)$ \\
\hline$c(\AA)$ & $13.8867(12)$ \\
\hline$\alpha\left(^{\circ}\right)$ & 90 \\
\hline$\beta\left(^{\circ}\right)$ & 90 \\
\hline$\gamma\left({ }^{\circ}\right)$ & 90 \\
\hline$V\left(\AA^{3}\right)$ & $485.05(6)$ \\
\hline$Z$ & 2 \\
\hline Density $\left(\mathrm{g} \mathrm{cm}^{-3}\right)$ & 5.226 \\
\hline Abs coeff $\left(\mathrm{mm}^{-1}\right)$ & 31.371 \\
\hline$F(000)$ & 672 \\
\hline GOF on $F^{2}$ & 1.114 \\
\hline$R_{1}$ and $w R_{2}$ (all data) ${ }^{\mathrm{a}}$ & $0.0587,0.1396$ \\
\hline$R_{1}$ and $w R_{2}(I>2 \sigma(I))^{\mathrm{a}}$ & $0.0571,0.1384$ \\
\hline
\end{tabular}

a) $\quad R_{1}(F)=\sum|| F_{o}|-| F_{c}|| / \sum\left|F_{o}\right|$,

$$
w R_{2}\left(F_{o}^{2}\right)=\left[\sum w\left(F_{o}^{2}-F_{c}^{2}\right)^{2} / \sum w\left(F_{o}^{2}\right)^{2}\right]^{1 / 2} .
$$

summarized in Table S2.

As shown in Fig. $2 \mathrm{a}$ and $\mathrm{b}, \mathrm{Na}_{4} \mathrm{Cu}_{3} \mathrm{TaAs}_{4}$ can be regarded to share similar structure with $\mathrm{NaFeAs}$ ("NaCuAs"). The crystal structure of $\mathrm{Na}_{4} \mathrm{Cu}_{3} \mathrm{TaAs}_{4}$ is constituted by double layers of $\mathrm{Na}$ cations sandwiched by anti-PbO-type $(\mathrm{Cu} / \mathrm{Ta})$ As layer which is the same as FeAs layer in NaFeAs. The stacking sequence along the $c$ axis is As- $(\mathrm{Cu} / \mathrm{Ta})-$ As-Na-Na-As.

Further analyzing the crystal structure, we find Ta arranges orderly. As shown in Fig. 2c-f, compared with the possible parent compound "NaCuAs", Ta in the $(\mathrm{Cu} / \mathrm{Ta})$ As layer forms a $\sqrt{2} \times \sqrt{2} \times 2$ superstructure re- lative to perfect $\mathrm{CuAs}$ layer in "NaCuAs". In the $a b$ plane, the distance of adjacent $\mathrm{Ta}$ is $\sqrt{2}$ times that of adjacent $\mathrm{Cu}$. Along the $c$ axis, the distance of adjacent $\mathrm{Ta}$ is twice that of adjacent $\mathrm{Cu}$. In fact, compounds with perfect anti$\mathrm{PbO}$-type $\mathrm{CuAs}$ layer have been already synthesized, such as $\mathrm{SrCu}_{2} \mathrm{As}_{2}$ [26]. While $\mathrm{SrCu}_{2} \mathrm{As}_{2}$ is a typical 122-type compound. Compared with $\mathrm{SrCu}_{2} \mathrm{As}_{2}, 25 \% \mathrm{Cu}$ is replaced by ordered $\mathrm{Ta}$, and single layer of $\mathrm{Sr}$ sandwiched by $\mathrm{CuAs}$ layers in $\mathrm{SrCu}_{2} \mathrm{As}_{2}$ is replaced by double layers of $\mathrm{Na}$. Due to orderly arrangement of $\mathrm{Ta}$, the crystal structure reduces symmetry and adopts the $I \overline{4} 2 m$ (121) space group. And the lattice constants of $\mathrm{Na}_{4} \mathrm{Cu}_{3} \mathrm{TaAs}_{4}$ are $a=$ 5.9101(3) $\AA$ and $c=13.8867$ (12) $\AA$. Thus, all peaks in the polycrystalline XRD pattern can be indexed with the new structure (see Fig. S2 in SI). And the polycrystalline XRD Rietveld refinement result is summarized in Table S3.

In order to investigate the electronic structure of the $\mathrm{Na}_{4} \mathrm{Cu}_{3} \mathrm{TaAs}_{4}$, we carried out XPS measurement on the single crystal samples. Fig. 3 shows the $\mathrm{Cu} 2 \mathrm{p}$, Ta 4f, As $3 \mathrm{~d}$ regions in the spectrum of $\mathrm{Na}_{4} \mathrm{Cu}_{3} \mathrm{TaAs}_{4}$. As shown in Fig. 3a, we compare the $\mathrm{Cu}$ valance of $\mathrm{Na}_{4} \mathrm{Cu}_{3} \mathrm{TaAs}_{4}$ with those of $\mathrm{CuO}$ and $\mathrm{SrCu}_{2} \mathrm{As}_{2}$ samples. The peak positions of $\mathrm{Cu} 2 \mathrm{p}_{1 / 2}$ and $\mathrm{Cu} 2 \mathrm{p}_{3 / 2}$ are at about 952.0 and $932.0 \mathrm{eV}$ respectively. The peak positions of $\mathrm{Cu}$ for the $\mathrm{Na}_{4} \mathrm{Cu}_{3} \mathrm{TaAs}_{4}$ single crystal are nearly the same as $\mathrm{SrCu}_{2} \mathrm{As}_{2}$ [27]. While the peak positions for divalent copper in $\mathrm{CuO}$ sample shift to higher binding energy, which are distinctly different from those of $\mathrm{Cu}^{1+}$. In addition, the XPS pattern of divalent copper has very intense satellite peak. Based on these, we determine that the valance state of $\mathrm{Cu}$ in the $\mathrm{Na}_{4} \mathrm{Cu}_{3} \mathrm{TaAs}_{4}$ is +1 oxidation state with fully occupied $3 \mathrm{~d}^{10}$ configuration. For the Ta $4 \mathrm{f}$ region, after the background was deduced with the Shirley function, two peaks could be observed. As shown in Fig. 3b, the low binding energy of $\mathrm{Ta} 4 \mathrm{f}_{7 / 2}$ peak at $25.5 \mathrm{eV}$ is slightly lower than that of $\mathrm{Ta}_{2} \mathrm{O}_{5}(26.5 \mathrm{eV})$, but much higher than that of $\mathrm{TaS}_{2}(23.60 \mathrm{eV})$. Therefore, the valence of $\mathrm{Ta}$ is extremely close to +5 . For the As $3 \mathrm{~d}$ region, only one peak could be observed at $40.29 \mathrm{eV}$. The binding energy of As $3 \mathrm{~d}$ is in accordance with the binding energy of GaAs and the valance is -3 . And the valence of

Table 2 Atomic coordinates and equivalent displacement parameters for $\mathrm{Na}_{4} \mathrm{Cu}_{3} \mathrm{TaAs}_{4}$

\begin{tabular}{|c|c|c|c|c|c|c|}
\hline Atom & Wyckoff & $x$ & $y$ & $z$ & Occup & $U_{\text {eq }}\left(\AA^{2}\right)$ \\
\hline $\mathrm{Nal}$ & $8 \mathrm{i}$ & $0.7329(16)$ & $0.7329(16)$ & $0.8259(9)$ & 1 & $0.023(3)$ \\
\hline $\mathrm{Cul}$ & $4 c$ & 0.5 & 1 & 0.5 & 1 & $0.017(2)$ \\
\hline $\mathrm{Cu} 2$ & $2 b$ & 1 & 1 & 0.5 & 1 & $0.045(2)$ \\
\hline Tal & $2 \mathrm{a}$ & 0.5 & 0.5 & 0.5 & 1 & $0.01(1)$ \\
\hline As 1 & $8 \mathrm{i}$ & $0.7381(4)$ & $0.7381(4)$ & $0.6069(2)$ & 1 & $0.014(1)$ \\
\hline
\end{tabular}



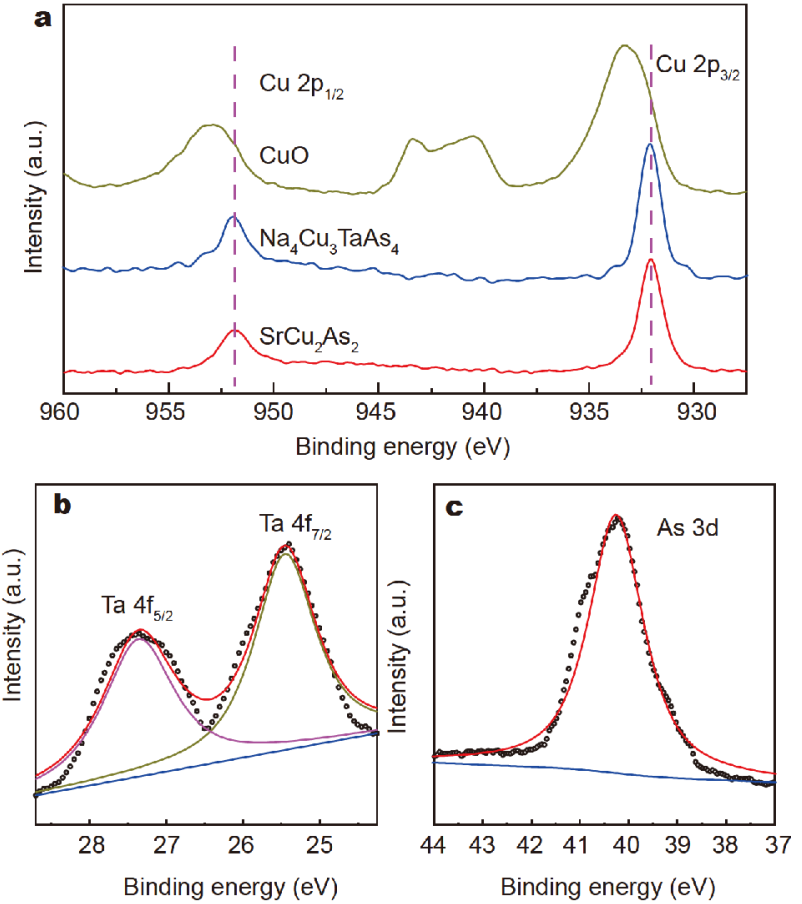

Figure 3 The XPS spectrum for $\mathrm{Na}_{4} \mathrm{Cu}_{3} \mathrm{TaAs}_{4}$. (a) The region of $\mathrm{Cu} 2 \mathrm{p}_{1 / 2}$ and $\mathrm{Cu} 2 \mathrm{p}_{3 / 2}$, compared with $\mathrm{CuO}$ and $\mathrm{SrCu}_{2} \mathrm{As}_{2}$ single crystals. (b) The region of $\mathrm{Ta} 4 \mathrm{f}_{5 / 2}$ and $\mathrm{Ta} 4 \mathrm{f}_{7 / 2}$. (c) The region of As $3 \mathrm{~d}$.

$\mathrm{Na}$ is +1 (see Fig. $\mathrm{S} 3$ in SI).

Then we determined the band structure of $\mathrm{Na}_{4} \mathrm{Cu}_{3} \mathrm{TaAs}_{4}$ by ARPES. The ARPES-intensity plot along the $\Gamma-\mathrm{M}$-A cut in the Brillouin-zone for $\mathrm{Na}_{4} \mathrm{Cu}_{3} \mathrm{TaAs}_{4}$ single crystal at room temperature is shown in Fig. $4 \mathrm{a}$. The calculated band structure for $\mathrm{Na}_{4} \mathrm{Cu}_{3} \mathrm{TaAs}_{4}$ is shown in Fig. 4b. As seen in Fig. 4a and b, the experimental dispersion relations are in good agreement with theoretical calculation. ARPES along the $\Gamma-\mathrm{M}$ direction in Fig. 4 a shows the hole-like bands centered at the $\mathrm{M}$ point.
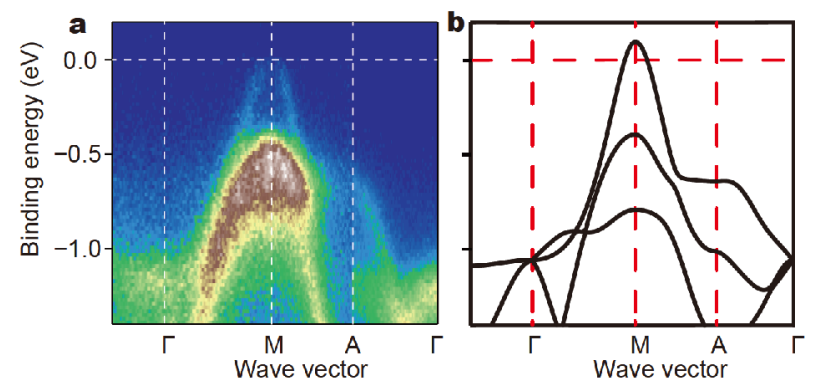

Figure 4 The electronic structure of $\mathrm{Na}_{4} \mathrm{Cu}_{3} \mathrm{TaAs}_{4}$. (a) Valence-band ARPES intensity of $\mathrm{Na}_{4} \mathrm{Cu}_{3} \mathrm{TaAs}_{4}$ measured along the $\Gamma-\mathrm{M}$-A cut at room temperature. (b) Calculated band structure obtained from the first-principles band-structure calculations for $\mathrm{Na}_{4} \mathrm{Cu}_{3} \mathrm{TaAs}_{4}$.

Fermi surface crosses the energy band, indicating that $\mathrm{Na}_{4} \mathrm{Cu}_{3} \mathrm{TaAs}_{4}$ is metallic with hole carriers. And the hole carrier concentration is estimated to be of the order of $10^{19} \mathrm{~cm}^{-3}$ according to the band structure.

The transport property and magnetic susceptibility of $\mathrm{Na}_{4} \mathrm{Cu}_{3} \mathrm{TaAs}_{4}$ single crystal are shown in Fig. 5. Fig. 5a shows the in-plane resistivity $\rho$ as a function of temperature over the range from 300 to $2 \mathrm{~K}$. According to the results, the temperature dependence of the resistivity indicates that the single crystal is metallic. And there is no superconductivity or other apparent phase transition down to $2 \mathrm{~K}$. At room temperature, the resistivity is about $10.78 \mathrm{~m} \Omega \mathrm{cm}$. We fit the resistivity data to the equation $\rho=a+b T^{2}$ in the temperature range $5-100 \mathrm{~K}$ and obtain value of $n=1.934$ which is close to 2, suggesting Fermi liquid behavior. The temperature dependence of the Hall coefficient $\left(R_{\mathrm{H}}\right)$ and carrier concentration $(n)$ are shown in the inset of Fig. 5a. The value of $R_{\mathrm{H}}$ is positive in the whole temperature range, which implies that hole-type charge carriers dominate the conduction in the $\mathrm{Na}_{4} \mathrm{Cu}_{3} \mathrm{TaAs}_{4}$. The carrier concentration is estimated to
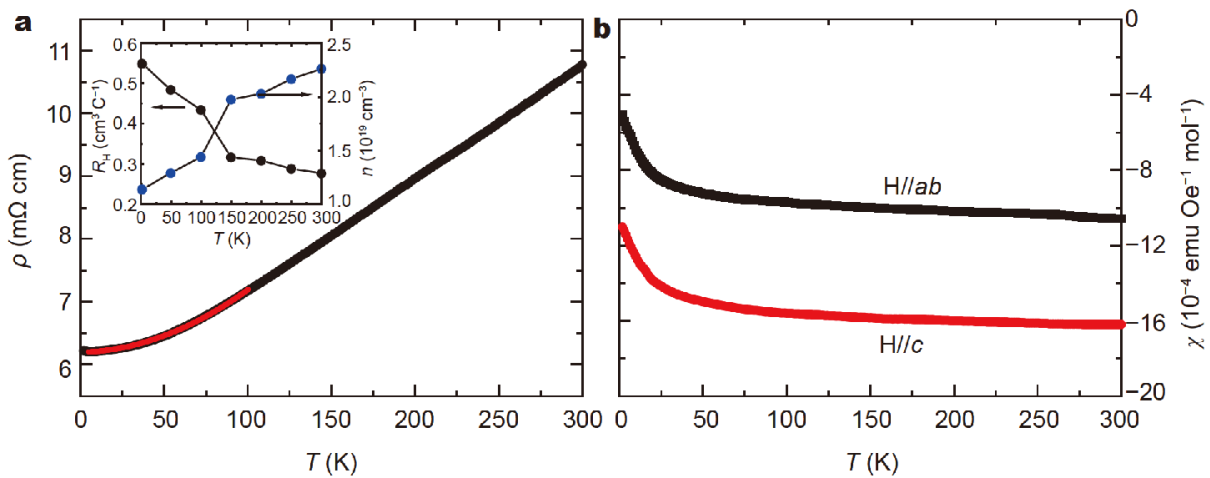

Figure 5 Resistivity and magnetic susceptibility of single crystal $\mathrm{Na}_{4} \mathrm{Cu}_{3} \mathrm{TaAs}_{4}$. (a) The temperature dependence of in-plane resistivity for the single crystal. The solid red curve is a fit of the resistivity in the temperature range 5-100 K. Inset: the temperature dependence of Hall coefficient $\left(R_{\mathrm{H}}\right)$ and carriers concentration $(n)$ at 2-300 K. (b) The temperature dependence of ZFC magnetic susceptibility for the single crystal at a magnetic field of 5 T applied along the $c$ axis $\left(\chi_{c}, \mathrm{H} / / c\right)$ and in the $a b$ plane $\left(\chi_{a b}, \mathrm{H} / / a b\right)$. 
be of the order of $10^{19} \mathrm{~cm}^{-3}$ by $n=1 / R_{\mathrm{H}} e$ using the single carrier model. The metallic feature and carrier concentration are consistent with the results estimated from ARPES. The lower carrier concentration is responsible for the larger resistivity.

The temperature dependence of zero-field-cooled (ZFC) magnetic susceptibility $\chi=M / H$ of the $\mathrm{Na}_{4} \mathrm{Cu}_{3} \mathrm{TaAs}_{4}$ single crystal from 2 to $300 \mathrm{~K}$ under an external field is presented in Fig. 5b, where $M$ is the measured magnetization of the $\mathrm{Na}_{4} \mathrm{Cu}_{3} \mathrm{TaAs}_{4}$ single crystal. The applied field $H$ of $5 \mathrm{~T}$ was aligned along the $c$ axis $\left(\chi_{c}, \mathrm{H} / / c\right)$ and in the $a b$ plane $\left(\chi_{a b}, \mathrm{H} / / a b\right)$. The $\chi(T)$ of the single crystal for both $\chi_{a b}$ and $\chi_{c}$ are negative and an obvious anisotropy with $\chi_{a b}>\chi_{c}$ is observed over the whole measured temperature range. The negative susceptibility and anisotropy are similar to that of copper arsenide $\mathrm{SrCu}_{2} \mathrm{As}_{2}$ [26]. The $\chi(T)$ of the single crystal in Fig. 5b shows weak temperature dependence without apparent magnetic transition down to $2 \mathrm{~K}$, which means there is no long range magnetic order in this material. Small Curie-Weiss tails are observed at low temperature for both $\chi_{a b}$ and $\chi_{c}$, probably due to the contribution of a small quantity of paramagnetic impurities in the sample. Absence of long range magnetic order is consistent with nonmagnetic +1 oxidation state of $\mathrm{Cu}$ and +5 oxidation state of Ta.

\section{DISCUSSION}

The $\mathrm{Cu}^{1+}$ oxidation state and $3 \mathrm{~d}^{10}$ electronic configuration are relatively stable, and the oxidability of arsenic is not strong enough to oxidize $\mathrm{Cu}$ to +2 oxidation state, so it is not strange that $\mathrm{Cu}$ in $\mathrm{Na}_{4} \mathrm{Cu}_{3} \mathrm{TaAs}_{4}$ has +1 oxidation state. In addition, according to the survey of the radii of the elements by Cordero et al. [28], As-As covalent bond distance is $2.38(8) \AA$. In $\mathrm{SrCu}_{2} \mathrm{As}_{2}$ with anti-PbO type CuAs layer, the value $d_{\mathrm{As}-\mathrm{As}}=2.470 \AA$ is close to the As-As covalent bond distance, yielding $\mathrm{As}^{2-}$ oxidation state $\left(\mathrm{As}^{-2}=[\mathrm{As}-\mathrm{As}]^{-4} / 2\right)$. However, for $\mathrm{Na}_{4} \mathrm{Cu}_{3} \mathrm{TaAs}_{4}$, the distance of As-As is $4.961 \AA$. The value is too large to prevent the formation of As-As covalent bond, which confirms that the oxidation state of As in this material is $\mathrm{As}^{3-}$ as discussed above. Therefore the crystal "NaCuAs" cannot be stabilized. But when $25 \% \mathrm{Cu}^{1+}$ are replaced by $\mathrm{Ta}^{5+}$, the structure can be stabilized because of realizing balance of valence state. In addition, according to the Shannon's tables [29], the ionic radii values of $\mathrm{Cu}^{1+}$ and $\mathrm{Ta}^{5+}$ are 0.60 and $0.64 \AA$ respectively. Their ionic radii values are very close, contributing to stabilizing the structure. In the materials with variants of anti-PbO-type layers, including $\mathrm{Ln}_{2} \mathrm{O}_{2} \mathrm{MSe}_{2}$ [30], $\mathrm{NaFe}_{0.5} \mathrm{Cu}_{0.5} \mathrm{As}$ and
$\mathrm{K}_{2} \mathrm{Fe}_{4} \mathrm{Se}_{5}$, transition metal ions or vacancies usually arrange orderly. This phenomenon makes us speculate that the superstructure induced by transition metal ordered arrangement in anti-PbO-type layer may be a kind of advantageous mode contributing to stabilizing the structure [30].

\section{CONCLUSIONS}

In summary, a new transition metal layered material, $\mathrm{Na}_{4} \mathrm{Cu}_{3} \mathrm{TaAs}_{4}$ single crystal, has been synthesized by a self-flux technique. This new material has layered structure, containing two layers of $\mathrm{Na}$ sandwiched by antiPbO-type $(\mathrm{Cu} / \mathrm{Ta})$ As layers. And in $(\mathrm{Cu} / \mathrm{Ta})$ As layers, $\mathrm{Ta}$ forms $\sqrt{2} \times \sqrt{2} \times 2$ superstructure compared with the related 111 type iron-based superconductor. $\mathrm{Cu}$ in the $\mathrm{Na}_{4} \mathrm{Cu}_{3} \mathrm{TaAs}_{4}$ is +1 oxidation state with a fully occupied $3 \mathrm{~d}^{10}$ configuration and $\mathrm{Ta}$ is +5 oxidation state with $4 \mathrm{f}^{14}$ electronic configuration. The valence and electronic configuration of $\mathrm{Cu}$ and $\mathrm{Ta}$ is the key to the structure stabilization. The band structure measured by ARPES is in good agreement with DFT calculation. And this material exhibits metallic behavior with p-type carriers and $T$-independent diamagnetic behavior.

Received 25 December 2019; accepted 9 January 2020;

published online 28 February 2020

1 Kamihara $\mathrm{Y}$, Watanabe $\mathrm{T}$, Hirano $\mathrm{M}$, et al. Iron-based layered superconductor $\mathrm{La}\left[\mathrm{O}_{1-x} \mathrm{~F}_{x}\right] \mathrm{FeAs}(x=0.05-0.12)$ with $T_{\mathrm{c}}=26 \mathrm{~K}$. J Am Chem Soc, 2008, 130: 3296-3297

2 Chen $\mathrm{XH}, \mathrm{Wu} \mathrm{T}, \mathrm{Wu} \mathrm{G}$, et al. Superconductivity at $43 \mathrm{~K}$ in $\mathrm{SmFeAsO}_{1-x} \mathrm{~F}_{x}$. Nature, 2008, 453: 761-762

3 Ren ZA, Lu W, Yang J, et al. Superconductivity at $55 \mathrm{~K}$ in ironbased F-doped layered quaternary compound $\operatorname{Sm}\left[\mathrm{O}_{1-x} \mathrm{~F}_{x}\right] \mathrm{FeAs}$. Chin Phys Lett, 2008, 25: 2215-2216

4 Rotter M, Tegel M, Johrendt D. Superconductivity at $38 \mathrm{~K}$ in the iron arsenide $\mathrm{Ba}_{1-x} \mathrm{~K}_{x} \mathrm{Fe}_{2} \mathrm{As}_{2}$. Phys Rev Lett, 2008, 101: 107006

5 Parker DR, Pitcher MJ, Baker PJ, et al. Structure, antiferromagnetism and superconductivity of the layered iron arsenide NaFeAs. Chem Commun, 2009, 16: 2189-2191

6 Hsu FC, Luo JY, Yeh KW, et al. Superconductivity in the PbO-type structure a-FeSe. Proc Natl Acad Sci USA, 2008, 105: 14262-14264

7 Guo J, Jin S, Wang G, et al. Superconductivity in the iron selenide $\mathrm{K}_{x} 2 \mathrm{Fe}_{2} \mathrm{Se}_{2}(0<x<1.0)$. Phys Rev B, 2010, 82: 180520

8 Yanagi $\mathrm{H}$, Kawamura R, Kamiya $\mathrm{T}$, et al. Itinerant ferromagnetism in the layered crystals LaCoOX (X=P, As). Phys Rev B, 2008, 77: 224431

9 Sefat AS, Singh DJ, Jin R, et al. Renormalized behavior and proximity of $\mathrm{BaCo}_{2} \mathrm{As}_{2}$ to a magnetic quantum critical point. Phys Rev B, 2009, 79: 024512

10 Emery N, Wildman EJ, Skakle JMS, et al. Giant magnetoresistance in oxypnictides (La,Nd)OMnAs. Chem Commun, 2010, 46: 67776779

11 Singh Y, Ellern A, Johnston DC. Magnetic, transport, and thermal properties of single crystals of the layered arsenide $\mathrm{BaMn}_{2} \mathrm{As}_{2}$. Phys 
Rev B, 2009, 79: 094519

12 Ueda $\mathrm{K}$, Inoue $\mathrm{S}$, Hirose $\mathrm{S}$, et al. Transparent p-type semiconductor: LaCuOS layered oxysulfide. Appl Phys Lett, 2000, 77: 2701-2703

13 Barreteau C, Pan L, Amzallag E, et al. Layered oxychalcogenide in the $\mathrm{Bi}-\mathrm{Cu}-\mathrm{O}-\mathrm{Se}$ system as good thermoelectric materials. Semicond Sci Technol, 2014, 29: 064001

14 Hiramatsu H, Ueda K, Kamiya T, et al. Synthesis of single-phase layered oxychalcogenide $\mathrm{La}_{2} \mathrm{CdO}_{2} \mathrm{Se}_{2}$ : Crystal structure, optical and electrical properties. J Mater Chem, 2004, 14: 2946-2950

15 McCabe EE, Free DG, Evans JSO. A new iron oxyselenide $\mathrm{Ce}_{2} \mathrm{O}_{2} \mathrm{FeSe}_{2}$ : Synthesis and characterisation. Chem Commun, 2011, 47: 1261-1263

16 Song Y, Yamani Z, Cao C, et al. A Mott insulator continuously connected to iron pnictide superconductors. Nat Commun, 2016, 7: 13879

17 Wang AF, Luo XG, Yan YJ, et al. Phase diagram and calorimetric properties of $\mathrm{NaFe}_{1-x} \mathrm{Co}_{x}$ As. Phys Rev B, 2012, 85: 224521

18 Sheldrick GM. SHELXS-2018, Programs for X-ray Crystal Structure Solution. Göttingen: University of Göttingen, 2018

19 Blöchl PE. Projector augmented-wave method. Phys Rev B, 1994, 50: $17953-17979$

20 Kresse G, Joubert D. From ultrasoft pseudopotentials to the projector augmented-wave method. Phys Rev B, 1999, 59: 1758-1775

21 Kresse G, Furthmüller J. Efficient iterative schemes for ab initio total-energy calculations using a plane-wave basis set. Phys Rev B, 1996, 54: 11169-11186

22 Perdew JP, Burke K, Ernzerhof M. Generalized gradient approximation made simple. Phys Rev Lett, 1996, 77: 3865-3868

23 Chu CW, Chen F, Gooch M, et al. The synthesis and characterization of LiFeAs and NaFeAs. Phys C-Supercond, 2009, 469: 326331

24 Zavalij P, Bao W, Wang XF, et al. Structure of vacancy-ordered single-crystalline superconducting potassium iron selenide. Phys Rev B, 2011, 83: 132509

25 Song YJ, Wang Z, Wang ZW, et al. Phase transition, superstructure and physical properties of $\mathrm{K}_{2} \mathrm{Fe}_{4} \mathrm{Se}_{5}$. EPL, 2011, 95: 37007

26 Anand VK, Perera PK, Pandey A, et al. Crystal growth and physical properties of $\mathrm{SrCu}_{2} \mathrm{As}_{2}, \mathrm{SrCu}_{2} \mathrm{Sb}_{2}$, and $\mathrm{BaCu}_{2} \mathrm{Sb}_{2}$. Phys Rev B, 2012, 85: 214523

27 Yan YJ, Cheng P, Ying JJ, et al. Structural, magnetic, and electronic transport properties of hole-doped $\mathrm{SrFe}_{2-x} \mathrm{Cu}_{x} \mathrm{As}_{2}$ single crystals. Phys Rev B, 2013, 87: 075105

28 Cordero B, Gómez V, Platero-Prats AE, et al. Covalent radii revisited. Dalton Trans, 2008, 21: 2832-2838

29 Shannon RD. Revised effective ionic radii and systematic studies of interatomic distances in halides and chalcogenides. Acta Cryst A, 1976, 32: 751-767

30 Ainsworth $\mathrm{CM}$, Wang $\mathrm{CH}$, Johnston $\mathrm{HE}$, et al. Infinitely adaptive transition-metal ordering in $\mathrm{Ln}_{2} \mathrm{O}_{2} \mathrm{MSe}_{2}$-type oxychalcogenides. Inorg Chem, 2015, 54: 7230-7238

Acknowledgements This work was supported by the National Natural Science Foundation of China (11888101 and 11534010), Anhui Initiative in Quantum Information Technologies (AHY160000), the Strategic Priority Research Program of Chinese Academy of Sciences (XDB25000000), the National Key Research and Development Program of the Ministry of Science and Technology of China (2016YFA0300201 and 2017YFA0303001), and the Key Research Program of Frontier Sciences, CAS, China (QYZDYSSW-SLH021).
Author contributions Chen X conceived and coordinated the project, and was responsible for the infrastructure and project direction. Meng $\mathrm{F}$ synthesized the samples. Meng F, Shi M, Cui S and Wang N performed the experiments. Peng K performed the theoretical calculation; Chen X, Meng F, Shi M, Ying J and Sun Z analyzed the data. Chen X, Meng F and Ying J wrote the manuscript. All authors contributed to the general discussion.

Conflict of interest The authors declare that they have no conflict of interest.

Supplementary information The supporting data are available in the online version of the paper. Accession codes: CCDC 1966119 contains the supplementary crystallographic data for this paper. These data can be obtained free of charge via www.ccdc.cam.ac.uk/data_request/cif, or by emailing data_request@ccdc.cam.ac.uk, or by contacting The Cambridge Crystallographic Data Centre, 12 Union Road, Cambridge CB2 1EZ, UK; fax: +441223 336033.

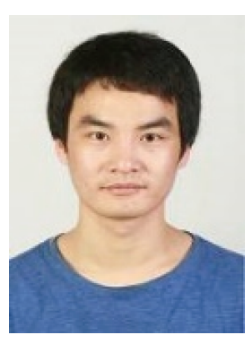

Fanbao Meng obtained his Bachelor degree in physics from Zhengzhou Universtiy. He is currently a $\mathrm{PhD}$ candidate in the University of Science and Technology of China (USTC) under the supervision of Prof. Xianhui Chen. His current research interest focuses on the exploration and characterization of layered functional material.

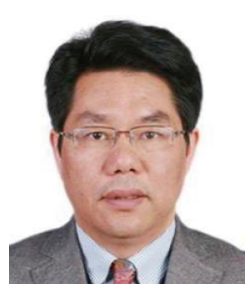

Xianhui Chen obtained his $\mathrm{PhD}$ degree in physics from USTC in 1992. In the same year, he began his research career in USTC and now holds the position of Professor in physics. His research focuses on the exploration and study of the physics of novel functional materials exhibiting superconductivity, novel magnetism, novel quantum properties, thermoelectricity, etc.

\section{一种新的过渡金属层状材料 $\mathrm{Na}_{4} \mathrm{Cu}_{3} \mathrm{TaAs}_{4}$ 的结构 和物理性质}

孟凡保 ${ }^{1}$, 石梦竹 ${ }^{1}$, 崔胜涛 ${ }^{2}$ 彭坤岭 ${ }^{1}$, 王乃䑤, 孙喆 ${ }^{2}$, 应剑俊 ${ }^{1}$, 陈仙辉 $1,3,4,5^{*}$

摘要 我们报道了一种新的过渡金属层状砷化物 $\mathrm{Na}_{4} \mathrm{Cu}_{3} \mathrm{TaAs}_{4}$ 的合 成、结构和物理性质. 这种材料采用 $I \overline{4} 2 m$ 空间群, 晶胞参数为 $a=5.9101(3) \AA, c=13.8867(12) \AA$. 这个材料的结构中包含两层 $\mathrm{Na}$, 而 $\mathrm{Na}$ 夹在反氧化铅型 $(\mathrm{Cu} / \mathrm{Ta}) \mathrm{As}$ 层之间, 类似于“ 111 ”型铁基超导 体 $\mathrm{NaFeAs}$. 过渡金属位由 $75 \%$ 的 $\mathrm{Cu}$ 和 $25 \%$ 的 Ta占据, $\mathrm{Ta}$ 形成了明确 的 $\sqrt{2} \times \sqrt{2} \times 2$ 超结构. $\mathrm{Cu}$ 和 $\mathrm{Ta}$ 分别为 +1 和 +5 价. 角分辨光电子能谱 测得的 $\mathrm{Na}_{4} \mathrm{Cu}_{3} \mathrm{TaAs}_{4}$ 能带结构能够和DFT计算结果良好地吻合. 角 分辨光电子能谱和输运测量均表明该材料表现为金属行为, 具有 $\mathrm{p}$ 型载流子. 磁化率测量表明该材料表现为几乎不依赖温度的抗磁 性. 这种新材料扩展了含有反氧化铅型层的材料系统, 并为进一步 研究该材料系统提供了一个很好的平台. 